\title{
Control over Structure and Properties in Nanocrystal Aerogels at the Nano-, Micro-, and Macroscale
}

\author{
Pascal Rusch, Dániel Zámbó, and Nadja C. Bigall*
}

Cite This: Acc. Chem. Res. 2020, 53, 2414-2424

Read Online

ACCESS | Lلll Metrics \& More | 回 Article Recommendations ｜ st Supporting Information

CONSPECTUS: The assembly of individual colloidal nanocrystals into macroscopic solvogels and aerogels introduced a new exciting type of material into the class of porous architectures. In these socalled nanocrystal gels, the structure and properties can be controlled and fine-tuned to the smallest details. Recently it was shown that by employing nanocrystal building blocks for such gel materials, the interesting nanoscopic properties can be conserved or even expanded to properties that are available neither in the nanocrystals nor in their respective bulk materials. In general, the production of these materials features the wet-chemical synthesis of stable nanocrystal colloids followed by their carefully controlled destabilization to facilitate arrangement of the nanocrystals into highly porous, interconnected networks. By isolation of the

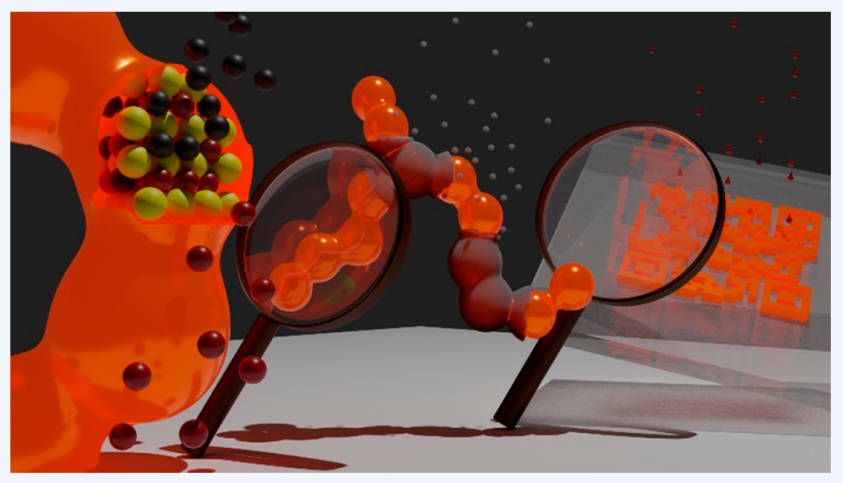
synthesis of the discrete building blocks from the assembly process, the electronic structure, optical properties, and structural morphology can be tailored by the myriad of procedures developed in colloidal nanocrystal chemistry. Furthermore, knowledge and control over the structure-property correlation in the resulting gel structures opens up numerous new ways for extended and advanced applications. Consequently, the amount of different materials converted to nanocrystal-based gel structures is rising steadily. Meanwhile the number of methods for assembly initiation is likewise increasing, offering control over the overall network structure and porosity as well as the individual nanocrystal building block connection. The resulting networks can be dried by different methods to obtain highly porous air-filled networks (aerogels) or applied in their wet form (solvogels). By now a number of different applications profiting from the unique advantages of nanocrystal-based gel materials have been realized and exploited in the areas of photocatalysis, electrocatalysis, and sensing.

In this Account, we aim to summarize the efforts undertaken in the structuring of nanocrystal-based network materials on different scales, fine-tuning of the individual building blocks on the nanoscale, the network connections on the microscale, and the macroscale structure and shape of the final construct. It is exemplarily demonstrated how cation exchange reactions (at the nanoscale), postgelation modifications on the nanocrystal networks (microscale), and the structuring of the gels via printing techniques (macroscale) endow the resulting nanocrystal gel networks with novel physicochemical, mechanical, and electrocatalytic properties. The methods applied in the more traditional sol-gel chemistry targeting micro- and macroscale structuring are also reviewed, showing their future potential promoting the field of nanocrystal-based aerogels and their applications.

\section{KEY REFERENCES}

- Zámbó, D.; Schlosser, A.; Rusch, P.; Lübkemann, F.; Koch, J.; Pfnür, H.; Bigall, N. C. A Versatile Route to Assemble Semiconductor Nanoparticles into Functional Aerogels by Means of Trivalent Cations. Small 2020, 16, 1906934. ${ }^{1}$ This work describes the formation and optical properties of nanocrystal gel networks (solvo- and aerogels) composed of interconnected nanorods or nanoplatelets. This method route enables the assembly of nanocrystals into functional gel structures at room temperature without thermal activation.

- Lübkemann, F.; Rusch, P.; Getschmann, S.; Schremmer, B.; Schäfer, M.; Schulz, M.; Hoppe, B.; Behrens, P.; Bigall, N. C.; Dorfs, D. Reversible Cation Exchange on
Macroscopic CdSe/CdS and CdS Nanorod Based Gel Networks. Nanoscale 2020, 12, 5038-5047..$^{2}$ This work demonstrates the feasibility and versatility of cation exchange on macroscopic nanocrystal gel structures. Cation exchange on $\mathrm{CdSe} / \mathrm{CdS}$ dot-in-rod and CdS nanorod based lyogels to $\mathrm{Cu}_{2-x} \mathrm{Se} / \mathrm{Cu}_{2-x} \mathrm{~S}$ and $\mathrm{Cu}_{2-x} \mathrm{~S}$ and toward further metal chalcogenide-based gel structures is presented.

Received: July 24, 2020

Published: October 8, 2020

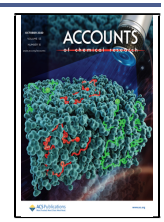




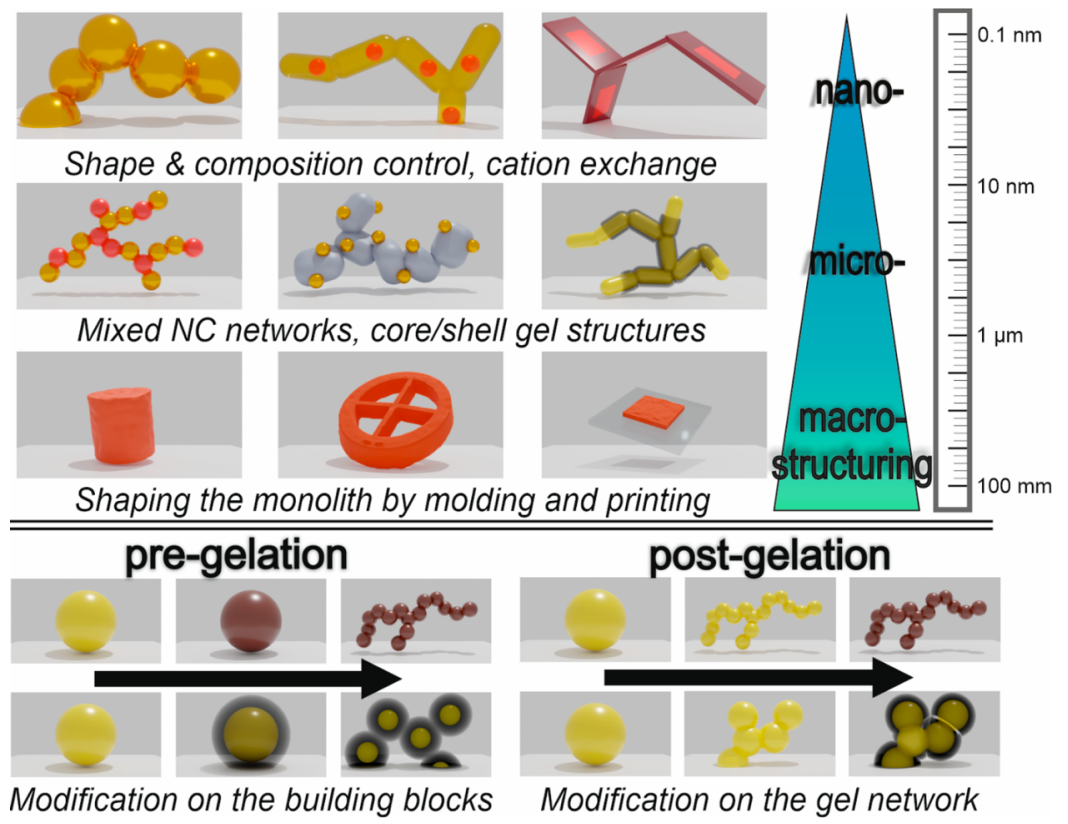

Figure 1. Manipulations of NC-based gels at different scale levels: nanostructuring (gels from shape- and composition-controlled NCs); microstructuring (gels from different NCs or postmodification of gels with a second material); macrostructuring (monoliths with tuned shape). Modifications performed on the NCs before assembly of the network (pregelation) or modifications on the assembled NC-based gel (postgelation).

- Rusch, P.; Niemeyer, F.; Pluta, D.; Schremmer, B.; Lübkemann, F.; Rosebrock, M.; Schäfer, M.; Jahns, M.; Behrens, P.; Bigall, N. C. Versatile Route to Core-Shell Reinforced Network Nanostructures. Nanoscale 2019, 11, 15270-15278. ${ }^{3}$ This work describes the formation of novel core-shell nanocrystal network structures, where the nanocrystals are assembled into a gel network followed by coating with a continuous metal oxide shell. The reinforced aerogels have significantly higher mechanical stability.

- Freytag, A.; Sánchez-Paradinas, S.; Naskar, S.; Wendt, N.; Colombo, M.; Pugliese, G.; Poppe, J.; Demirci, C.; Kretschmer, I.; Bahnemann, D. W.; Behrens, P.; Bigall, N. C. Versatile Aerogel Fabrication by Freezing and Subsequent Freeze-Drying of Colloidal Nanoparticle Solutions. Angew. Chem., Int. Ed. 2016, 55, 1200-1203. ${ }^{4}$ In this work, a versatile approach to fabricate self-supported nanocrystal aerogels via the so-called cryogelation method is described. The applicability of the method for noble metal, metal oxide, and semiconductor nanocrystals, as well as their macrostructuring possibilities, are presented.

\section{INTRODUCTION}

Aerogels represent a class of materials that can be fascinating even to a layperson due to their low density and exceptionally high specific surface area. ${ }^{5,6}$ In general, "aerogel” is used to describe a porous network structure (consisting of long chain macromolecules or even interconnected nanoscopic building blocks) in which the pores are filled with air. While the backbone is formed in wet conditions, the solvent has to be extracted under the conservation of the filigree network structure. Consequently, special drying techniques have to be employed. The origin and material of the network are usually not part of the definition. Already at the first successful generation of aerogels, ${ }^{7}$ numerous different materials have been converted to aerogels, and there is "no reason why this list may not be extended indefinitely" ${ }^{7}$ "The central idea of aerogel formation is to avoid the capillary forces usually acting on the network during drying, which would cause a collapse of the highly porous network structure. Supercritical drying is one of the most common methods for producing appropriate aerogels. In this process, the solvent (mostly liquid $\mathrm{CO}_{2}$ ) is brought above its critical point, usually within an autoclave, and is then carefully released in the form of gas. In the supercritical state, there is no difference between the liquid and the gaseous form of the fluid in the gel. Therefore, no meniscus is formed, and the capillary forces are heavily reduced. In most cases, a solid network structure is generated by "classical" solgel chemistry approaches. With the more widespread understanding and control over nanoparticle syntheses, however, the idea was born to use nanocrystals (NCs) as building blocks for gel-like structures. ${ }^{8,9}$ Soon after, the first generation of NCbased aerogels was described, ${ }^{10-12}$ and this opened up a new field in the area of NC research. By combination of isolated $\mathrm{NC}$ synthesis, which allows close control over the interesting properties of NCs, with the assembly of these NCs into porous network structures, it is possible to generate macroscopic structures retaining the unique size-dependent properties of the NC building blocks like high surface-to-volume ratio or their optical properties (as a consequence of the quantum size effect). ${ }^{12}$ The preservation of the nanoscopic properties can be attributed to the retained size, size distribution, shape, and composition of the building blocks upon gelation. The gelation of NC building blocks is a tool to bridge the nanoscopic and the macroscopic world. Since the introduction of these NCbased aerogels, the number of different gelation methods has steadily increased to broaden the horizon of the applicable nanomaterials. The main cornerstones are the original oxidative removal of NC surface ligands ${ }^{9-12}$ by methods like $\mathrm{pH}$-dependent techniques, ${ }^{13}$ use of specific ligands linked together by metal cation complexes, ${ }^{14}$ light-induced gelation, ${ }^{15}$ rapid freezing of $\mathrm{NC}$ solutions, ${ }^{4}$ and nonoxidative ligand removal by trivalent cations. ${ }^{1}$ Likewise, the catalogue of 
different materials that could be synthesized as NCs and assembled into gel-like networks has been expanded starting with different semiconductors, for example, CdSe, CdS, PbS, or $\mathrm{ZnS},{ }^{12}$ and metal oxides, ${ }^{16,17}$ phosphides, ${ }^{18,19}$ and nitrides, ${ }^{20}$ as well as noble metal NCs. ${ }^{21,22}$ The potential applications of NC-based network structures range from electro- ${ }^{23-26}$ and photocatalysis $^{27-31}$ to (spectro)electrochemical sensing ${ }^{32,33}$ and even thermoelectric applications. ${ }^{34}$ Notably, mechanical and operational stabilities are the drawbacks of conventional NC-based gels, and some of our strategies (discussed below) aim to diminish these to make use of advantages like tunable (opto-)electronical properties and the retained high accessible surface area, which is essential for all surface-driven processes.

The development of NC-based gels ${ }^{6}$ as well as the different methods and underlying theory ${ }^{35}$ have been widely reviewed already. Accordingly, this Account focuses on recent achievements that go a different way, using the variety and customizability of NC chemistry and the assembly of these NCs. Like gels bridge the nanoscopic scale of their building blocks to the macroscopic dimensions of the assembled monolith, the properties of these materials can be influenced by tuning the structure at different levels of scale. From the atomic or nanoscopic composition and shape of the building blocks and the network to the (larger nanoscopic or herecalled) microscopic structure and interparticle connections within the network and to the final macroscopic shape of the monolith (see also Figure 1 for illustration). The borders between these categories are faded, and a strict classification is often not possible. Still, a look at the size scale at which a modification to the material takes place can be helpful in structuring the options available, from the modification of single building blocks to influencing the entire network. This Account follows a similar structure. At the same time, a second distinction can be made by the chosen synthesis sequence. Essentially, the formed networks are solely interconnected NCs, and with the extensive catalogue of methods and tools to modify NCs, the question must be asked if it is possible to transfer these methods to be applied to an already existing network. This offers two distinct points at which the networks can be influenced: pre- and postgelation (see also Figure 1 for illustration). The first is investigated thoroughly by tuning the nanoscopic building blocks wet-chemically and by choosing an adequate gelation route. The second option, namely, the possibilities of network modification after the NC gelation, is rarely discussed. As this field is steadily advancing further, we aim to showcase the relation of the structures that can be forged with NC-based gels at different scales by fine-tuning before and after the assembly and the resulting properties.

\section{NANOSTRUCTURING I: TAILORING THE COMPOSITION AND SHAPE OF THE BUILDING BLOCKS}

One of the main advantages in the formation of porous macroscopic network structures from nanoparticle building blocks is access to the extensively developed library of colloidal nanoparticle syntheses. ${ }^{36-38}$ With this tool, the properties and the composition of these building blocks and in turn the properties of the resulting gel materials can be fine-tuned. The dedicated synthesis of the tailored NCs first of all enables shape-controlled building blocks affecting the resulting aerogel structures. It was shown that the use of anisotropic NCs, that is, rods, tetrapods, or nanoplatelets, leads to increased mechanical stability, as well as increased accessible surface area of the assembled networks in comparison to those of networks from quasispherical NCs. ${ }^{39}$ To further increase the total surface area of the gel network, the use of hollow noble metal NCs as building blocks has also been described. ${ }^{40}$

Despite these building block shape-dependent properties, colloidal synthesis has a further advantage: various kinds of nanoparticles can be synthesized with great control over the faceting. As an example of facet- and shape-controlled semiconductor NC building blocks, we recently reported on the gelation of semiconductor nanoplatelets (NPLs), ${ }^{41}$ nanostructures with a tunable thickness of only a few atomic monolayers and because of that having unique properties even within the class of nanomaterials, ${ }^{42,43}$ such as narrow emission spectra and minimal Stokes shift (see Figure 2d,e). Due to the crystal structure of the original NPL building blocks, the resulting network only exhibits basically one type of crystal facet, ${ }^{41}$ illustrating the connection of control over the building blocks and control over the network. Additionally, using a nonoxidative approach (using trivalent cations), $\mathrm{CdSe} / \mathrm{CdS}$ as well as $\mathrm{CdSe} / \mathrm{CdTe}$ core/crown NPLs have also been
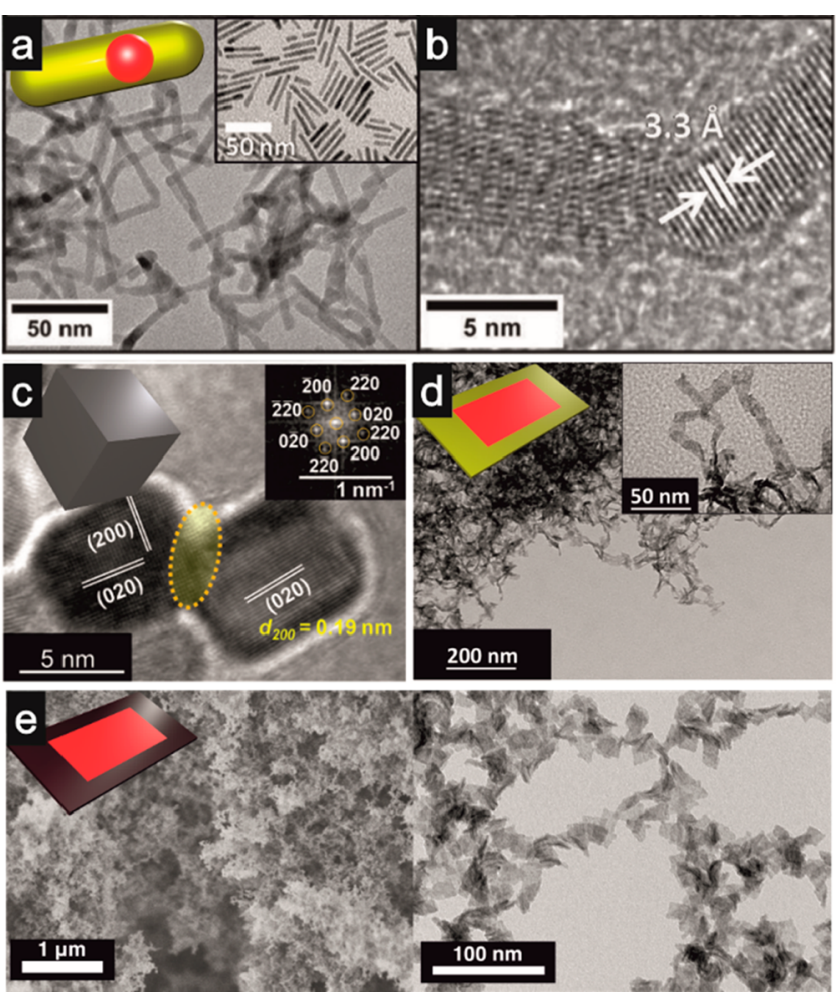

Figure 2. Examples for NC-based gels from shape- and compositioncontrolled building blocks: (a, b) CdSe/CdS dot/rod NCs, (c) Pt cubes, (d) $\mathrm{CdSe} / \mathrm{CdS}$ core/crown nanoplatelets (NPLs), and CdSe/ $\mathrm{CdTe}$ core/crown nanoplatelets as schematically displayed in the top left corner for each material. (a) Gels from CdSe/CdS dot/rod NCs and (inset) the rod building blocks and (b) higher magnification of the connection between the building blocks. Adapted from ref 48 . Copyright 2015 Wiley-VCH Verlag GmbH \& Co KGaA, Weinheim. (c) High resolution image of interconnected Pt nanocubes forming 3D network with only (100) as the exposed crystal facet. Adapted from ref 44. Copyright 2017 American Chemical Society. (d) TEM micrograph of an aerogel from $\mathrm{CdSe} / \mathrm{CdS}$ core/crown NPLs. Adapted from ref 41. Copyright 2016 American Chemical Society. (e) (left) SEM and (right) TEM images of aerogel structures obtained from CdSe/CdTe core/crown NPLs. Adapted from ref 1 . Published by WILEY-VCH Verlag GmbH \& Co. KGaA, Weinheim. 
successfully gelated into hyperbranched solvo- and aerogels with preservation of their optical properties. Moreover, in this case, also the band-engineered type-I or type-II alignment in the hetero-nanoplatelets as derived from wet-chemical synthesis could be transferred to the macroscopic scale. ${ }^{1}$ As an example from using tailored noble metal NCs, the gelation of shape-controlled $\mathrm{Pt}$ nanocubes has to be mentioned (see Figure 2c) ${ }^{44}$ Similarly to NPLs, the shape of the cubic building blocks forces the produced network to only exhibit one crystallographic facet. This enables their utilization, as has been shown, in facet-selective catalytic reactions. ${ }^{44}$

Apart of the advantages of an extremely high degree of control over size and shape when employing colloidal synthesis in modified sol-gel chemistries as described above, the second important advantage is the possibility to tune the nanoparticle composition as well. Especially the use of hetero-nanostructures as building blocks for hydrogels and aerogels has attracted remarkable attention. In the field of noble metal NC-based gels, exhaustive work has been performed to tailor NC composition via use of alloyed bi- and multimetallic NC building blocks for electrocatalytic applications. ${ }^{23-25}$ In addition to mixed metal gels, also hetero-nanoparticles of a metal and a semiconductor domain have been employed as building blocks for aerogelation, such as $\mathrm{Au}$ and $\mathrm{Ag}$ decorated CdS NCs. ${ }^{45,46}$ The third example for nanostructured building blocks in gels is the combination of two (or more) semiconductor compartments within the NC building blocks. For example, already quite soon after the introduction of NCbased aerogels, the step from single material NCs to heterostructures based on more than one material has been taken. In the first instance, the use of $\mathrm{CdSe} / \mathrm{ZnS}$ core/shell NCs led to the conservation of the photoluminescence properties of the building blocks within the interconnected network due to the type-I band alignment of the two materials. ${ }^{47}$

A further important band-aligned hetero-nanocrystal system was chosen by our group recently demonstrating how composition and shape control of band engineered nanorods can contribute to a new generation of aerogels exhibiting distinct physical properties. We synthesized and deeply investigated gel-networks based on photoluminescent CdSe/ CdS dot-in-rod nanostructures (see Figures 2a,b and $3 a$ ) due to their interesting electronic structure and the resulting optical properties. ${ }^{48}$ The direct connection of the nanocrystals in these heterostructures results in drastically prolonged exciton lifetimes in comparison to those of the building blocks (see Figure 3c). The distinct properties of prolonged exciton lifetimes have been attributed to a delocalization of the excited electrons over the network, which is possible due to the CdS crystal-to-crystal type connection of the rods within the network (as shown in Figure $3 \mathrm{~b}$ ). At the same time, excited holes remain confined to the $\mathrm{CdSe}$ cores. The combination of these two behaviors results in a decreased overlap of the respective wave functions and a slower recombination rate, ${ }^{48}$ which enables the utilization of the generated charge carriers in photo(electro)chemical sensing. ${ }^{32}$ Theoretical calculations show that these prolonged exciton lifetimes of the gels cannot be attributed to a delocalization of the electron in the ground excited state. Instead, higher excited states play a crucial role in the charge carrier dynamics within the gel. Because these higher excited states are energetically near each other, their thermal mixing can be assumed (see Figure 3d). In turn and in agreement with this theory, the exciton lifetimes decrease with

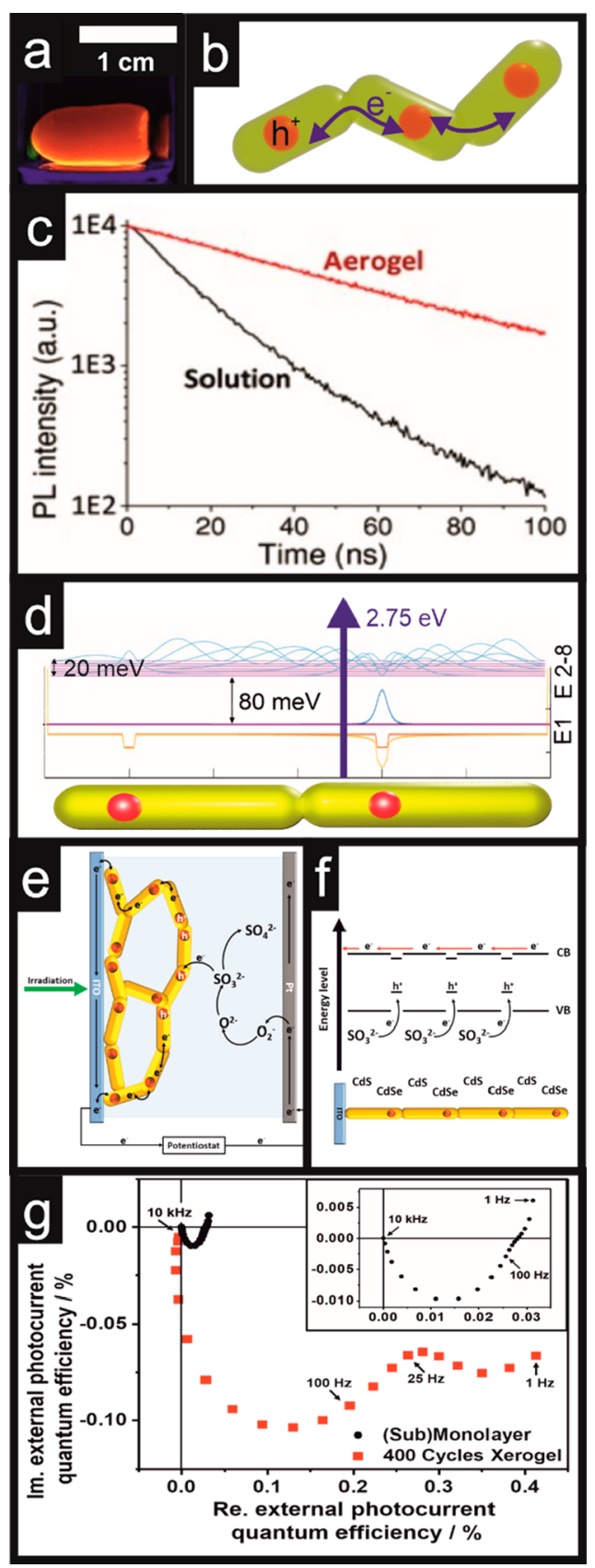

Figure 3. Influence of nanostructured building blocks on the properties of the resulting network structure in the $\mathrm{CdSe} / \mathrm{CdS}$ dot/ rod system. (a) Photograph of a CdSe/CdS dot/rod NC-based aerogel and (b) schematic depiction of the mobility of the excited electron within the network. (c) Drastically increased exciton lifetimes in the network structure compared to the NCs in solution. Adapted from ref 48. Copyright 2015 WILEY-VCH Verlag GmbH \& Co. $\mathrm{KGaA}$, Weinheim. (d) Theoretical calculation of the wave function of an excited electron in two connected nanocrystals with the delocalization visible for higher excited states. Adapted from ref 60 . Copyright 2019, American Chemical Society. (e) Schematic of electrochemical processes in CdSe/CdS NC-based gel and (f) their diode behavior. Adapted from ref 66. Copyright 2020 American Chemical Society. (g) IMPS measurements of the gels showing a charge carrier transport within the network as second semicircle at lower frequencies (see SI for details). Adapted from ref 68. Published by WILEY-VCH Verlag GmbH \& Co. KGaA, Weinheim. 

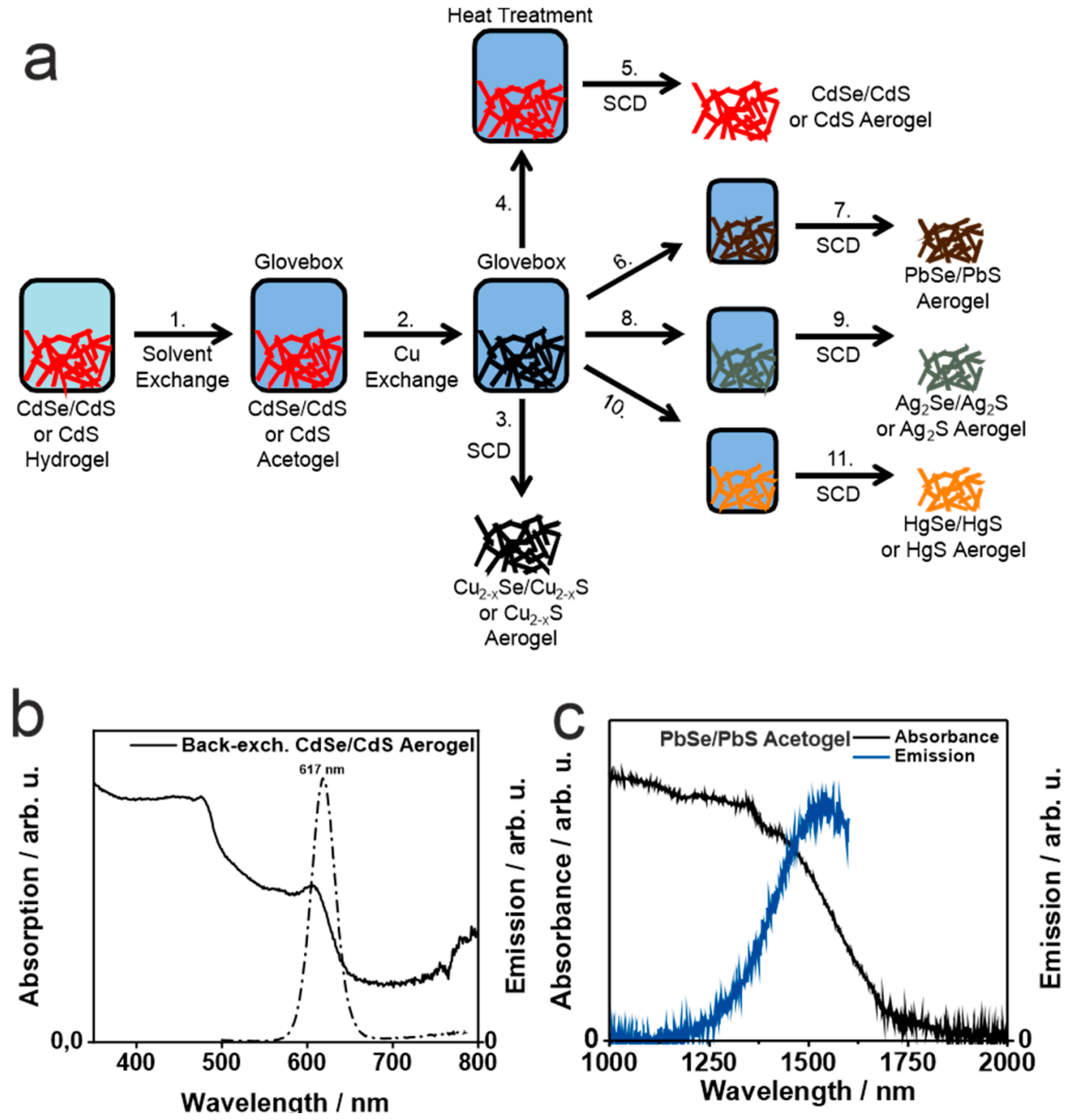

Figure 4. (a) Steps of cation exchange procedure on CdSe/CdS NC-based gel networks toward $\mathrm{Cu}_{2-x} \mathrm{Se} / \mathrm{Cu}_{2-x} \mathrm{~S}$ and $\mathrm{Cu}{ }_{2-x} \mathrm{~S}, \mathrm{PbSe} / \mathrm{PbS}, \mathrm{Ag}_{2} \mathrm{Se} /$ $\mathrm{Ag}_{2} \mathrm{~S}, \mathrm{Ag}_{2} \mathrm{~S}, \mathrm{HgSe} / \mathrm{HgS}$, and $\mathrm{HgS}$ aerogels. (b) Absorption and emission spectra of back-exchanged CdSe/CdS aerogel and (c) $\mathrm{PbSe} / \mathrm{PbS}$ acetogel. Adapted from ref 2 . Published by the Royal Society of Chemistry.

lower temperature as the contribution of the higher excited states within the intermixed states decreases. These structures were examined spectroelectrochemically as well (Figure 3e,f): with linear sweep voltammetry (LSV) and intensity modulated photocurrent spectroscopy (IMPS, Figure $3 \mathrm{~g}$ ), the possibility of conductance of electrons in the network was also confirmed (see SI for the details). This example shows that nanoparticle aerogels with a specially chosen band structure of the building blocks and the right way of interconnection can lead to new properties that are not accessible by the building blocks themselves nor by the bulk materials.

\section{NANOSTRUCTURING II: ADAPTING THE COMPOSITION AFTER GELATION}

Remarkably, a process of postsynthetic modification of a NC gel network was described as early as $2009,{ }^{49}$ only a few years after the first NC-based gels have were prepared. In this case, the very powerful method of cation exchange was applied to a NC network. Combining gelation techniques and cation exchange offers the possibility to first create an intricate nanostructure along an already well-paved route followed by changing the composition of the resulting architecture. During the process, novel compositions, structures, and phases that would be difficult or even impossible to synthesize straight-up can be obtained. ${ }^{50-52}$

In the first application of this technique to NC-based network structures, CdSe-based gels had been converted to $\mathrm{Ag}_{2} \mathrm{Se}$ - and PbSe-based ones. After this first showcase, the idea had not been mentioned again for several years, until very recently. ${ }^{2}$ Recognizing the great potential of transferring one (macroscopic) material into another, which is only possible for nanoporous materials, our group recently extended the cation exchange procedure on gels by applying it to networks based on anisotropic $\mathrm{CdS}$ nanorods and band engineered $\mathrm{CdSe} / \mathrm{CdS}$ dot/rod heterostructures (see above). This procedure was performed along the established cation exchange route for IIVI semiconductor NCs by first exchanging the cation to $\mathrm{Cu}(\mathrm{I})$, which then offers access to a plethora of materials as detailed in Figure 3a. We were able to show the complete reversibility of the process exchanging cadmium to copper inside the NCs and back to cadmium with restoration of the photoluminescence properties of the initial networks. By exchange with lead, it was also possible to generate an IR-emissive $\mathrm{PbSe} / \mathrm{PbS}$-based network (Figure 4c), even though the emission prior to the modification was in the visible wavelength region. ${ }^{2}$ In conclusion, the application of cation exchange processes developed for colloidal NCs can be transferred to NC-based 
network structures, even with complex compositions or defined band alignment, as well as NC-based gels with defined building block shapes. Besides enabling the modification of their composition at the nanoscale, the shape of the nanoparticles remains unaltered. Note that such ion exchange reactions are not possible in bulk monoliths, but the ability to perform this material transformation is a specialty for gels due to their inherently nanoporous structure. In combination with the tuned building blocks (see Nanostructuring I), this technique can, for example, help us to realize various type-I and type-II band alignments leading to a vast mine of bandengineered nanocrystal gels. An analogue to the colloidal NC cation exchange (where a robust $\mathrm{NC}$ synthesis can be used to afterward generate delicate materials), it can additionally be employed to generate networks based on robust NC materials and then transform these to the desired products. This route thereby circumvents the lengthy process of adapting gelation procedures to sensitive compounds.

\section{MICROSTRUCTURING I: NETWORKS FROM MULTIPLE BUILDING BLOCKS}

Apart from combining two materials in the building blocks (e.g., heteronanoparticles) as discussed above, the combination of different building blocks into one network structure has also been shown as a feasible possibility. By simple mixing, achieving arbitrary distributions of nanoparticles, the component distribution due to local inhomogeneities is on a larger scale than that employing hetero-nanoparticles. Even though most of the components will still vary on the tens to hundreds of nanometer scale, we have chosen to account this rather as sub-micrometer scale and therefore as microstructuring, in order to emphasize that here the component distribution varies on a larger scale than that in the hetero-nanoparticle building blocks case. The mixing-of-components route was demonstrated with mixtures of different noble metal NCs where the addition of $\mathrm{Ag} \mathrm{NCs}$ to $\mathrm{Au}$ or Pt NCs improved the network formation. ${ }^{21}$ The combination of noble metal and semiconductor NCs into one network structure has also been reported. The interaction between metallic parts and semiconducting parts can be studied via the fluorescence of the latter. ${ }^{13,15,33-55}$ The metal-semiconductor contact manifests itself in the introduction of new decay pathways and therefore changes the fluorescence kinetics. ${ }^{15,53,55}$ The metal-semiconductor material combination and the charge-carrier separation within such structures suggests their applicability as photocatalysts, for example, in $\mathrm{CO}_{2}$ photoreduction. ${ }^{16,28,29}$ A combination of two different semiconducting $\mathrm{NC}$ building blocks showed emission differing from the emission of their colloidal mixture, demonstrating energy transfer within the network and resulting in white emitting aerogels. ${ }^{56}$ The route usually employed to obtain all of these structures is the separate synthesis of the two individual NC building blocks, combining the two colloidal solutions, and performing cogelation of the two components.

By now methods have been described to more closely control the structure of these networks with regards to the contact points of the two components. The surface ligands of the individual NC building blocks can be used to facilitate segregation of the building blocks into their respective homogeneous networks or an intermixing into one heterogeneous network. This behavior has been demonstrated for a metal oxide-noble metal NC combination employing a gelation technique developed in our group entitled cryoaer- ogelation. The rapid freezing of the NC solution generates small ice crystallites that force the NCs effectively toward the gaps between the ice crystals, pressing them together and finally forming a network (see Figure 5a). ${ }^{4}$ Cryogelation can be
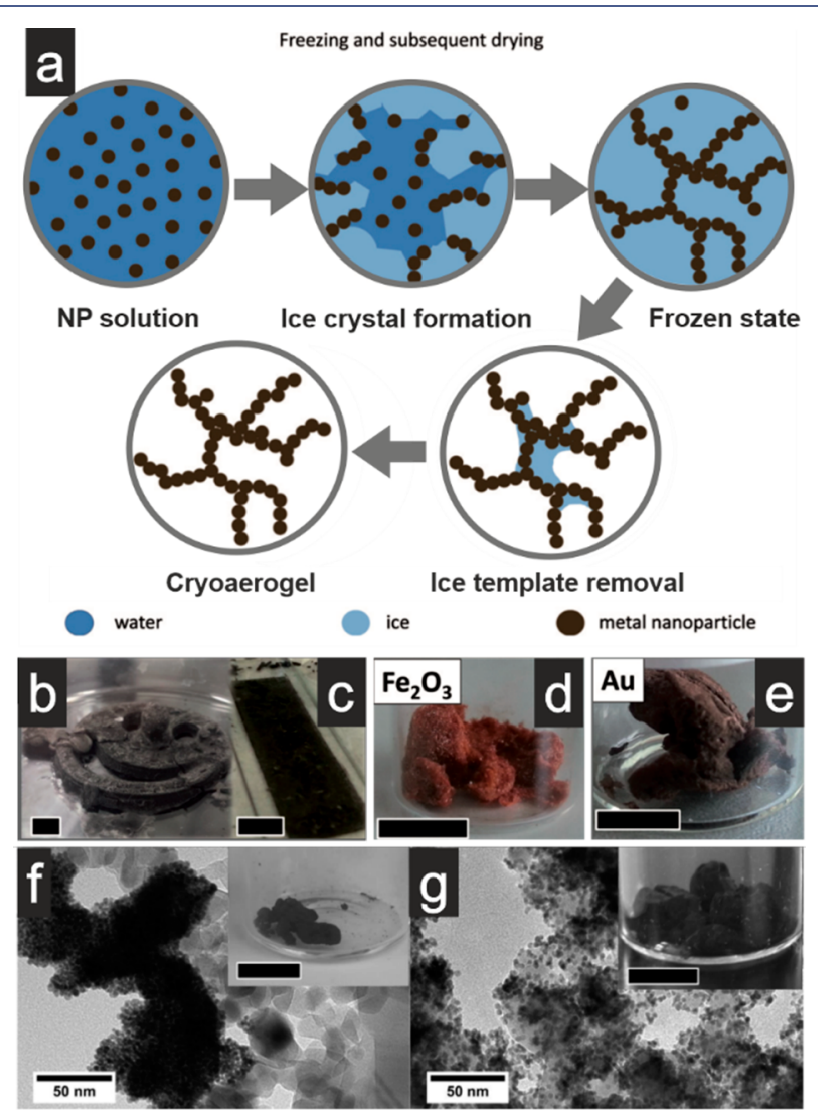

Figure 5. NC-based aerogels produced by cryoaerogelation. (a, top) Freezing mechanism of a droplet of metal nanoparticle colloid in liquid nitrogen from (left) colloidal solution to (right) frozen system and (a, bottom) subsequent removal of the ice template by lyophilization. Examples for a variety of shapes possible by cryoaerogelation route: (b) Smiley in a Petri dish. (c) Thin film on glass slide. Photographs of aerogels of (d) $\mathrm{Fe}_{2} \mathrm{O}_{3}$ and (e) $\mathrm{Au}$ (scale bar $1 \mathrm{~cm}$ ). Adapted from ref 4. Copyright 2016 Wiley-VCH Verlag $\mathrm{GmbH} \&$ Co KGaA, Weinheim. Mixed $\mathrm{TiO}_{2}$ and Pt NC-based cryoaerogels with controlled material distribution by (f) phase separation or (g) intermixing. Adapted from ref 27. Copyright 2018 American Chemical Society.

applied to various types of NCs (different shapes, dots, rods, or platelets of different materials like metal chalcogenides, metal oxides, or noble metals $)^{4,27,32,57}$ as it is based completely on the mechanical forces (Figure $5 \mathrm{~d}, \mathrm{e}$ ). In the case of gels based on a mixture of NCs, the surface charge of the two components was adjusted by the choice of surface ligands to be either equally charged positively resulting in a segregation of the components or opposingly charged resulting in a heterogeneous network with both components equally distributed (see Figure $5 \mathrm{f}, \mathrm{g}$ ). ${ }^{27}$ Similarly, when two semiconductor NC building blocks are combined, two homogeneous networks or one intermixed heterogeneous network could be generated by tuning the assembly kinetics of the oxidative gelation via the length of the surface ligands employed. $^{58}$ 


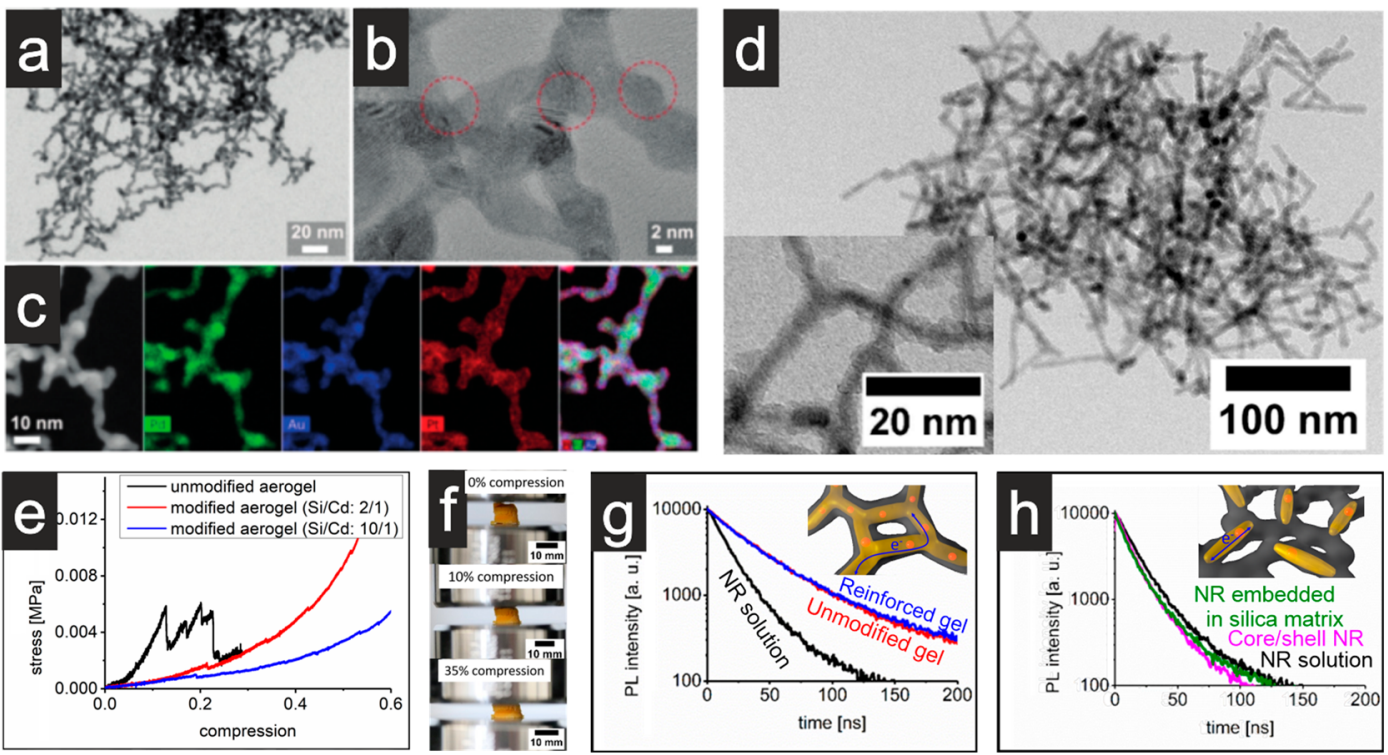

Figure 6. Postsynthetically modified, core-shell structured NC-based aerogels: (a) $\mathrm{Pd}_{10} \mathrm{Au}-\mathrm{Pt}$ core-shell aerogel, (b) higher magnification, and (c) its elemental distribution. Adapted from ref 59. Copyright 2018 Wiley-VCH Verlag GmbH \& Co. KGaA, Weinheim. (d) CdSe/CdS dot/rod NC network modified with silica after network formation. Physical properties of gels from panel d: (e) Mechanical measurement of silica shellmodified and unmodified $\mathrm{CdSe} / \mathrm{CdS}$ aerogels by compression test and (f) photographs at various points of the mechanical measurement. Adapted from ref 3. Published by The Royal Society of Chemistry. $(\mathrm{g}, \mathrm{h})$ Differences in optical properties depending on the synthesis sequence: fluorescence decay measurements of $(\mathrm{g})$ network formation first and $(\mathrm{h})$ silica modification first. Adapted from ref 60. Copyright 2019 American Chemical Society.

\section{MICROSTRUCTURING II: CORE-SHELL STRUCTURED NETWORKS}

The vast potential of NC modification procedures has been mentioned earlier with regards to tuning the individual NC building blocks for network formation (i.e., pregelation modifications such as seed mediated growth), but their application on the already existing NC assemblies (networks) is seldom described, especially concerning macroscopic or monolithic assemblies such as NC aerogels. Consequently, these procedures would provide access to otherwise unachievable materials. As an example, regarding the growth of shells by a seeded growth procedure, (i) modification of the NC building blocks pregelation would result in the gel being a network of interconnected core-shell structured NCs, while (ii) modification postgelation would result in the gel being a continuous, interconnected core network surrounded continuously with a shell material. These two structures will therefore be essentially different in their microstructure and their resulting properties: in the first case, the core NCs are spatially separated in the resulting gel structures (that is, the shell acts like a spacer between then quasi-independent nanoparticles), while the postgelation modified structure possesses a continuous shell along the entire interconnected NC backbone.

A first example of postgelation routes for multimetallic core-shell networks produced by galvanic replacement (shown in Figure $6 a-c$ ) was presented as a promising catalyst for the oxygen reduction reaction (ORR). ${ }^{59} \mathrm{~A}$ different approach for chemical modification methods of NCs is the already well-established seed mediated growth method. We recently explored the idea of transferring this approach from colloidal NC solutions to NC gel networks on the example of silica shell growth (as detailed in SI). With careful adjustments of synthesis parameters, the $\mathrm{CdSe} / \mathrm{CdS} \mathrm{dot} / \mathrm{rod}$ core-silica shell (see Figure 6d) was expanded to a titania shell system as well as a $\mathrm{Au}-\mathrm{Ag}$ core system, thereby coating continuous networks of several kilometers in length with a shell only a few nanometers thick. ${ }^{3}$ The postgelation modification resulted in reinforced core-shell structured networks with considerably improved mechanical stability as compared to an unmodified gel. This can be seen by steep drops in stress indicating parts of the monolith breaking apart, which is not observed in silica shell modified aerogels, see Figure 6e,f.

The importance of the synthesis sequence was outlined in the Introduction and applied in this work. By postgelation modification, a core-shell network structure of interconnected $\mathrm{CdSe} / \mathrm{CdS}$ dot/rod NCs surrounded by a continuous silica shell can be produced (Figure 6d); pregelation modification on the other hand results in a very much different structure of spatially separated CdSe/CdS dot/rod core NCs connected via their silica shells (practicably embedded within a silica matrix), as is schematically shown in Figure $6 \mathrm{~g}, \mathrm{~h} .{ }^{60}$ This leads to two very similar systems with the same composition but with an essentially different form of connection or isolation of the core NCs. The interparticle connection within the semiconductor NCs is of central importance and manifests itself in drastically increased fluorescence lifetimes (see section Nanostructuring I), which could not be found if the NCs had been physically isolated from each other by a pregelation silica growth (see Figure $6 \mathrm{~g}, \mathrm{~h}$ and Figure 3). ${ }^{60}$ The example of systematically coupling and decoupling the NC building blocks of the network shows that the cooperation of precise network design and synthesis together with elaborate investigation techniques are necessary to understand such complex structures.

\section{MACROSTRUCTURING: SHAPING THE MONOLITH BY MOLDING AND PRINTING}

Both the postgelation cation exchange and the microstructural modification by shell growth procedures discussed earlier 

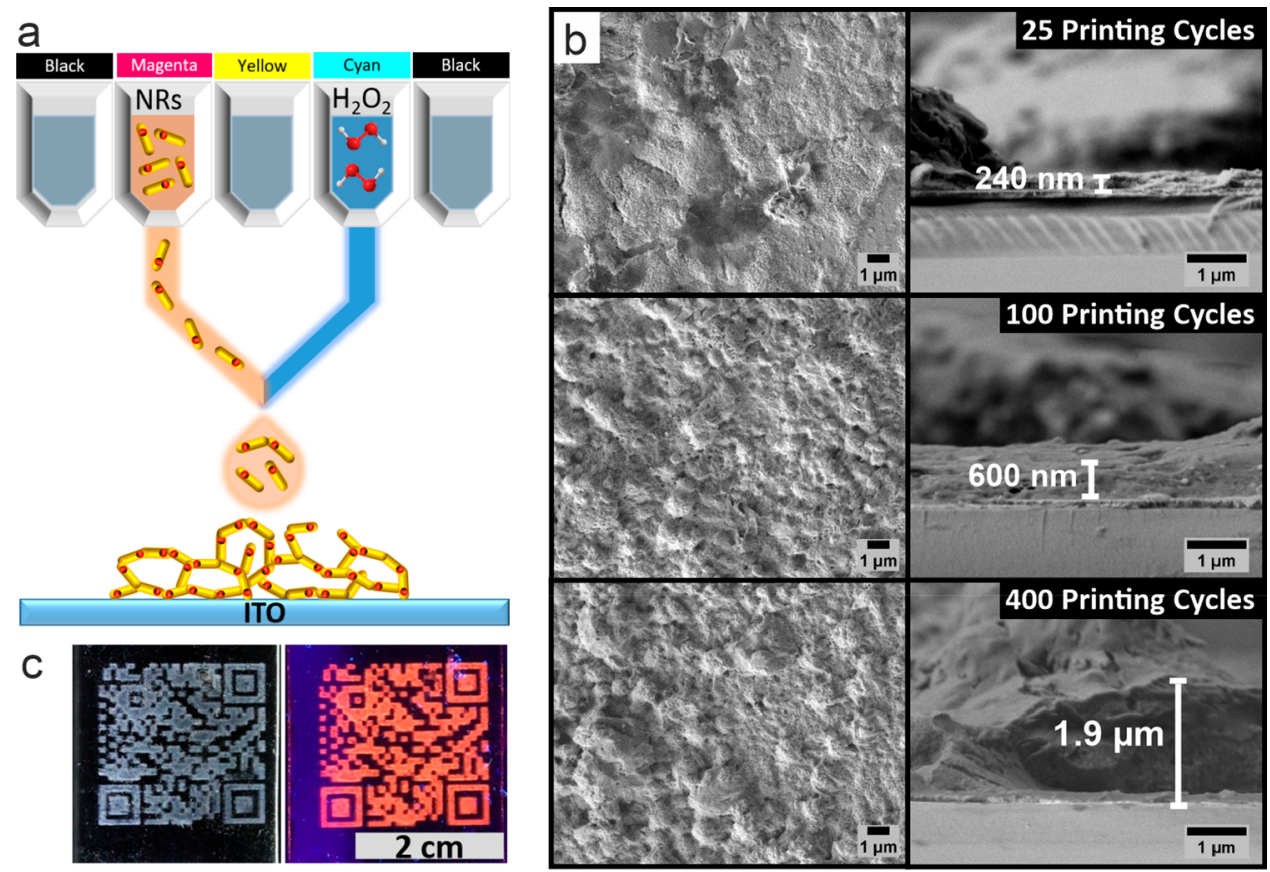

Figure 7. Gelation via inkjet printing (GelVIP) process. (a) Schematic illustration of printing process for automatized manufacturing of 3D semiconductor network coated electrodes. Adapted from ref 68. Published by WILEY-VCH Verlag GmbH \& Co. KGaA, Weinheim. (b) SEM images from top view (left) and cross-section view (right) of CdSe/CdS xerogel substrates with different thicknesses (top to bottom): 25, 100, and 400 printing cycles. Adapted from ref 66. Copyright 2020 American Chemical Society. (c) Photographs of a printed, fully functioning QR code (with resolution of $285 \mathrm{dpi}$ ) consisting of a porous nanorod xerogel network under ambient (left) and UV (right) illumination. Adapted from ref 68. Published by WILEY-VCH Verlag GmbH \& Co. KGaA, Weinheim.

enable us to broaden the functionalities of NC-based network structures considerably, giving access to more complex structures. For applications, however, it is also interesting to govern the macroscopic structure via controlling the NC distribution inside a sol-gel-based monolith ${ }^{61-63}$ or shaping the NC-based monolith by molding and printing. A monolithic gel tends to take its macroscopic shape from the container used in the gelation step, allowing shaping by the use of molds. It was shown that a mixture of CdTe and Au NCs can be gelated and simultaneously molded. ${ }^{13}$ During our development of the cryoaerogelation method mentioned above based on rapid freezing of a concentrated aqueous NC solution, we also successfully applied a molding approach to macroscopically shape a NC-based gel. The cryogel is generated within preformed molds to shape the final monolith (Figure $5 \mathrm{~b}, \mathrm{c}$ ). ${ }^{4}$ The application of NC-based networks, for example, in electrochemical applications, has been discussed eagerly in the past. To use a gel in electrochemical sensing, contacting the gel to an electric circuit is inevitably needed. As the gel itself is usually too mechanically fragile to be contacted directly, a common method is the deposition of the gel onto a conductive substrate to form an electrode. The subsequent dip coating of the electrode with a NC solution and the gelation agent resulted in a few nanometer thick gel film on the electrode, which could then be electrochemically investigated. ${ }^{64,65}$ In our works, we first applied similar techniques for electrode production based on doctor blade casting of a NC solution and rapid freezing ${ }^{32}$ or the gelation of NC solutions within molds. 66

These above-mentioned methods are suitable to generate coated gel electrodes having basic shapes and consisting of one single type of NCs. The printing of gels would be a promising approach for fabrication of, for example, gel-based electrodes as it allows for the creation of laterally resolved shapes while using less material and leaving the remaining electrode surface undisturbed compared to the more traditional dip- or spincoating. This motivated us to experiment with printing as a technique for manufacturing NC-based electrodes. Our first experiments led to dense mono- and multilayers of semiconductor NC on a conductive electrode surface by means of a commercial inkjet printer. ${ }^{67}$

By combining the knowledge about macroscopic gelation, the printing of semiconductor NCs, and a simultaneous gelation of the ink, we were able to realize a setup to perform "Gelation via Inkjet Printing" ${ }^{68}$ This platform has numerous advantages: low cost, easy adaptation, and versatility in the used NCs as well as the desired printed pattern. The process is schematically shown in Figure 7a (for more details, please refer to the SI). Using this platform, NC-based porous gel-coated electrodes with controlled gel layer thicknesses of a few hundred nanometers up to several micrometers and a lateral resolution of almost $300 \mathrm{dpi}$ as evident by the printing of a fully operational $\mathrm{QR}$ code pattern (see prepared electrodes and structured QR code in Figure $7 \mathrm{~b}, \mathrm{c})$ were obtained. ${ }^{68}$ In contrast to the dense and nonporous directly printed nanocrystals, the printed gels have significantly higher porosity and distinct photoelectrochemical properties, such as the ability to transport charge carriers and high and unidirectional photocurrents. Spectroelectrochemical characterization revealed the diode behavior of the printed gels and enabled the kinetic study of the hydration of the coatings. ${ }^{68}$ Long-term LSV measurements showed the influence of gel swelling and rehydration of the network due to its porous nature. The generated photocurrent increases with the time in the electrolyte with first-order kinetics. ${ }^{68}$ This supports the approach of hierarchically layered porosity as a way to increase 
the diffusion throughout the network and provides quickly applicable electrodes with spatial control via inkjet printing. ${ }^{68}$

\section{SUMMARY AND OUTLOOK}

The field of NC-based aerogels has come a long way since the introduction of these materials more than a decade ago driven forward by the advances in nanochemistry. The growing insight into the properties and synthesis of nanocrystalline materials helps to develop even more complex and welldesigned networks from even more finely tuned building blocks. But the networks themselves have shown to be more than the sum of their building blocks. The connection of the NCs in the network can lead to novel, fascinating properties, which might not exist in colloidal solutions at all. The process of material development in this area does not have to stop with the assembly of meticulously tailored building blocks into gels.

In this Account, we have shown how the structures of NCbased gels can be used to influence their properties on different levels of scale at different points during the process. We have summarized the more traditional methods focusing on tuning the building blocks and their assembly (pregelation) and detailed some of the recent examples of postgelation modification, from the subnanometer cation exchange to transforming network materials via the core-shell modification on the microscale to the controlled macroscale patterning of gels by inkjet printing. Techniques like these allow for the generation of networks from materials that are usually not accessible, for the mechanical reinforcement of networks, for material conservation, for hierarchically structured porosity of networks, and so much more. The works on this idea have for now been few and far between, but they might allow for the circumvention of problems commonly encountered in bringing NC-based aerogels into application. The shown approaches pave the way toward the solution of problems emerging in this field. Materials that cannot be gelated could perhaps be generated by postgelation cation exchange, intrinsically fragile networks could be reinforced, and slow diffusion through the network might be improved by structuring. These efforts have brought the gel structures closer to applications such as photo(electro)catalysis or sensing. Therefore, this approach needs to be and will be explored more often in the future. The exploration of using techniques to further structure NC-based aerogels to endow them with multifunctionality has only just begun, and the works presented here can be seen as careful first steps toward this idea.

\section{ASSOCIATED CONTENT}

\section{Supporting Information}

The Supporting Information is available free of charge at https://pubs.acs.org/doi/10.1021/acs.accounts.0c00463.

More details on electrochemical characterization of gels, the cation exchange procedure, core-shell structured gels, and the printing of gels (PDF)

\section{AUTHOR INFORMATION}

\section{Corresponding Author}

Nadja C. Bigall - Institute of Physical Chemistry and Electrochemistry, Leibniz Universität Hannover, 30167

Hannover, Germany; Cluster of Excellence PhoenixD

(Photonics, Optics, and Engineering - Innovation Across
Disciplines), 30167 Hannover, Germany; 이잉.org/00000003-0171-1106; Email: nadja.bigall@pci.uni-hannover.de

Authors

Pascal Rusch - Institute of Physical Chemistry and Electrochemistry, Leibniz Universität Hannover, 30167 Hannover, Germany

Dániel Zámbó - Institute of Physical Chemistry and Electrochemistry, Leibniz Universität Hannover, 30167

Hannover, Germany; 이이이.org/0000-0001-7671-039X

Complete contact information is available at:

https://pubs.acs.org/10.1021/acs.accounts.0c00463

\section{Author Contributions}

The manuscript was written through contributions of all authors. All authors have given approval to the final version of the manuscript.

Notes

The authors declare no competing financial interest.

\section{Biographies}

Pascal Rusch was born in Hanover in 1993. After receiving a B.Sc. in Chemistry from Friedrich-Schiller-Universität Jena and a M.Sc. in Material and Nanochemistry from Leibniz Universität Hannover, he joined the group of Prof. Bigall as a Ph.D. student in 2016. His research interests cover the synthesis, characterization, and postsynthetic modification of nanocrystal-based assemblies.

Dániel Zámbó was born in Budapest, Hungary, in 1989. He received a B.Sc. and M.Sc. in Chemical Engineering from Budapest University of Technology and Economics in 2011 and 2013 followed by his Ph.D. in Chemistry from the same institution in 2016. He was a postdoctoral researcher at the Institute of Technical Physics and Materials Science of the Hungarian Academy of Sciences. Later, he joined the group of Prof. Bigall at Leibniz Universität Hannover where he is currently a postdoctoral researcher. His research interests include plasmonics, single-particle spectroscopy, nanostructured interfaces, and self-assembled nanostructures from semiconductor and hybrid nanocrystals.

Nadja C. Bigall was born in Munich in 1979. She graduated in physics at Ludwig Maximilians Universität in 2005 followed by a doctorate at TU Dresden in 2009 in physical chemistry. After postdoctoral work at Italian Institute of Technology and at PhilippsUniversität Marburg, she built up her own research group at Leibniz Universität Hannover, where she became associate professor in 2017 and full professor in 2018. Her research interests are the synthesis, characterization, and structure-property correlation of functional nanostructures, such as colloidal nanocrystals and assemblies thereof.

\section{ACKNOWLEDGMENTS}

This work has received funding from the European Research Council (ERC) under the European Union's Horizon 2020 research and innovation program (Grant Agreement No. 714429). Furthermore, the project leading to these results has in part received funding from the German Federal Ministry of Education and Research (BMBF) within the framework of the program NanoMatFutur (Support Code 03X5525) and from the Deutsche Forschungsgemeinschaft (DFG, German Research Foundation) under Germany's Excellence Strategy within the Cluster of Excellence PhoenixD (EXC 2122, Project ID 390833453). N.C.B. thanks the DFG (Research Grant BI 1708/4-1) for funding. The authors thank the 
Laboratory of Nano and Quantum Engineering (LNQE) of the Leibniz Universität Hannover for support.

\section{REFERENCES}

(1) Zámbó, D.; Schlosser, A.; Rusch, P.; Lübkemann, F.; Koch, J.; Pfnür, H.; Bigall, N. C. A Versatile Route to Assemble Semiconductor Nanoparticles into Functional Aerogels by Means of Trivalent Cations. Small 2020, 16, 1906934.

(2) Lübkemann, F.; Rusch, P.; Getschmann, S.; Schremmer, B.; Schäfer, M.; Schulz, M.; Hoppe, B.; Behrens, P.; Bigall, N. C.; Dorfs, D. Reversible Cation Exchange on Macroscopic CdSe/CdS and CdS Nanorod Based Gel Networks. Nanoscale 2020, 12, 5038-5047.

(3) Rusch, P.; Niemeyer, F.; Pluta, D.; Schremmer, B.; Lübkemann, F.; Rosebrock, M.; Schäfer, M.; Jahns, M.; Behrens, P.; Bigall, N. C. Versatile Route to Core-Shell Reinforced Network Nanostructures. Nanoscale 2019, 11, 15270-15278.

(4) Freytag, A.; Sánchez-Paradinas, S.; Naskar, S.; Wendt, N.; Colombo, M.; Pugliese, G.; Poppe, J.; Demirci, C.; Kretschmer, I.; Bahnemann, D. W.; Behrens, P.; Bigall, N. C. Versatile Aerogel Fabrication by Freezing and Subsequent Freeze-Drying of Colloidal Nanoparticle Solutions. Angew. Chem., Int. Ed. 2016, 55, 1200-1203.

(5) Hüsing, N.; Schubert, U. Aerogels-Airy Materials: Chemistry, Structure, and Properties. Angew. Chem., Int. Ed. 1998, 37, 22-45.

(6) Ziegler, C.; Wolf, A.; Liu, W.; Herrmann, A. K.; Gaponik, N.; Eychmüller, A. Modern Inorganic Aerogels. Angew. Chem., Int. Ed. 2017, 56, 13200-13221.

(7) Kistler, S. S. Coherent Expanded Aerogels and Jellies. Nature 1931, 127, 741-741.

(8) Gacoin, T.; Lahlil, K.; Larregaray, P.; Boilot, J. P. Transformation of CdS Colloids: Sols, Gels, and Precipitates. J. Phys. Chem. B 2001, 105, 10228-10235.

(9) Gacoin, T.; Malier, L.; Boilot, J. P. New Transparent Chalcogenide Materials Using a Sol-Gel Process. Chem. Mater. 1997, 9, 1502-1504.

(10) Mohanan, J. L.; Brock, S. L. A New Addition to the Aerogel Community: Unsupported CdS Aerogels with Tunable Optical Properties. J. Non-Cryst. Solids 2004, 350, 1-8.

(11) Mohanan, J. L.; Arachchige, I. U.; Brock, S. L. Porous Semiconductor Chalcogenide Aerogels. Science 2005, 307, 397-400.

(12) Arachchige, I. U.; Mohanan, J. L.; Brock, S. L. Sol-Gel Processing of Semiconducting Metal Chalcogenide Xerogels: Influence of Dimensionality on Quantum Confinement Effects in a Nanoparticle Network. Chem. Mater. 2005, 17, 6644-6650.

(13) Sekiguchi, S.; Niikura, K.; Iyo, N.; Matsuo, Y.; Eguchi, A.; Nakabayashi, T.; Ohta, N.; Ijiro, K. PH-Dependent Network Formation of Quantum Dots and Fluorescent Quenching by $\mathrm{Au}$ Nanoparticle Embedding. ACS Appl. Mater. Interfaces 2011, 3, 41694173.

(14) Sayevich, V.; Cai, B.; Benad, A.; Haubold, D.; Sonntag, L.; Gaponik, N.; Lesnyak, V.; Eychmüller, A. 3D Assembly of AllInorganic Colloidal Nanocrystals into Gels and Aerogels. Angew. Chem., Int. Ed. 2016, 55, 6334-6338.

(15) Hendel, T.; Lesnyak, V.; Kühn, L.; Herrmann, A. K.; Bigall, N. C.; Borchardt, L.; Kaskel, S.; Gaponik, N.; Eychmüller, A. Mixed Aerogels from $\mathrm{Au}$ and CdTe Nanoparticles. Adv. Funct. Mater. 2013, 23, 1903-1911.

(16) Heiligtag, F. J.; Rossell, M. D.; Süess, M. J.; Niederberger, M. Template-Free Co-Assembly of Preformed $\mathrm{Au}$ and $\mathrm{TiO} 2$ Nanoparticles into Multicomponent 3D Aerogels. J. Mater. Chem. 2011, 21, 16893-16899.

(17) Rechberger, F.; Mercandetti, C.; Tervoort, E.; Niederberger, M. Colloidal Nanocrystal-Based BaTiO3 Xerogels as Green Bodies: Effect of Drying and Sintering at Low Temperatures on Pore Structure and Microstructures. Langmuir 2017, 33, 280-287.

(18) Hitihami-Mudiyanselage, A.; Senevirathne, K.; Brock, S. L. Assembly of Phosphide Nanocrystals into Porous Networks: Formation of InP Gels and Aerogels. ACS Nano 2013, 7, 1163-1170.

(19) Hitihami-Mudiyanselage, A.; Senevirathne, K.; Brock, S. L. Bottom-up Assembly of Ni2P Nanoparticles into Three-Dimensional
Architectures: An Alternative Mechanism for Phosphide Gelation. Chem. Mater. 2014, 26, 6251-6256.

(20) Deshmukh, R.; Tervoort, E.; Käch, J.; Rechberger, F.; Niederberger, M. Assembly of Ultrasmall Cu3N Nanoparticles into Three-Dimensional Porous Monolithic Aerogels. Dalt. Trans. 2016, $45,11616-11619$.

(21) Bigall, N. C.; Herrmann, A.-K.; Vogel, M.; Rose, M.; Simon, P.; Carrillo-Cabrera, W.; Dorfs, D.; Kaskel, S.; Gaponik, N.; Eychmüller, A. Hydrogels and Aerogels from Noble Metal Nanoparticles. Angew. Chem., Int. Ed. 2009, 48, 9731-9734.

(22) Leventis, N.; Chandrasekaran, N.; Sotiriou-Leventis, C.; Mumtaz, A. Smelting in the Age of Nano: Iron Aerogels. J. Mater. Chem. 2009, 19, 63-65.

(23) Cai, B.; Wen, D.; Liu, W.; Herrmann, A. K.; Benad, A.; Eychmüller, A. Function-Led Design of Aerogels: Self-Assembly of Alloyed PdNi Hollow Nanospheres for Efficient Electrocatalysis. Angew. Chem., Int. Ed. 2015, 54, 13101-13105.

(24) Du, R.; Hu, Y.; Hübner, R.; Joswig, J. O.; Fan, X.; Schneider, K.; Eychmüller, A. Specific Ion Effects Directed Noble Metal Aerogels: Versatile Manipulation for Electrocatalysis and Beyond. Sci. Adv. 2019, 5, eaaw4590.

(25) Liu, W.; Rodriguez, P.; Borchardt, L.; Foelske, A.; Yuan, J.; Herrmann, A.-K.; Geiger, D.; Zheng, Z.; Kaskel, S.; Gaponik, N.; Kötz, R.; Schmidt, T. J.; Eychmüller, A. Bimetallic Aerogels: HighPerformance Electrocatalysts for the Oxygen Reduction Reaction. Angew. Chem., Int. Ed. 2013, 52, 9849-9852.

(26) Cai, B.; Dianat, A.; Hübner, R.; Liu, W.; Wen, D.; Benad, A.; Sonntag, L.; Gemming, T.; Cuniberti, G.; Eychmüller, A. Multimetallic Hierarchical Aerogels: Shape Engineering of the Building Blocks for Efficient Electrocatalysis. Adv. Mater. 2017, 29, 1605254.

(27) Freytag, A.; Günnemann, C.; Naskar, S.; Hamid, S.; Lübkemann, F.; Bahnemann, D.; Bigall, N. C. Tailoring Composition and Material Distribution in Multicomponent Cryoaerogels for Application in Photocatalysis. ACS Appl. Nano Mater. 2018, 1, 6123-6130.

(28) Heiligtag, F. J.; Cheng, W.; De Mendonça, V. R.; Süess, M. J.; Hametner, K.; Günther, D.; Ribeiro, C.; Niederberger, M. SelfAssembly of Metal and Metal Oxide Nanoparticles and Nanowires into a Macroscopic Ternary Aerogel Monolith with Tailored Photocatalytic Properties. Chem. Mater. 2014, 26, 5576-5584.

(29) Rechberger, F.; Niederberger, M. Translucent NanoparticleBased Aerogel Monoliths as 3-Dimensional Photocatalysts for the Selective Photoreduction of $\mathrm{CO}_{2}$ to Methanol in a Continuous Flow Reactor. Mater. Horiz. 2017, 4, 1115-1121.

(30) Wan, W.; Zhang, R.; Ma, M.; Zhou, Y. Monolithic Aerogel Photocatalysts: A Review. J. Mater. Chem. A 2018, 6, 754-775.

(31) Demirci, C.; Marras, S.; Prato, M.; Pasquale, L.; Manna, L.; Colombo, M. Design of Catalytically Active Porous Gold Structures from a Bottom-up Method: The Role of Metal Traces in CO Oxidation and Oxidative Coupling of Methanol. J. Catal. 2019, 375, 279-286.

(32) Schlosser, A.; Meyer, L. C.; Lübkemann, F.; Miethe, J. F.; Bigall, N. C. Nanoplatelet Cryoaerogels with Potential Application in Photoelectrochemical Sensing. Phys. Chem. Chem. Phys. 2019, 21, 9002-9012.

(33) Yao, Q.; Brock, S. L. Optical Sensing of Triethylamine Using CdSe Aerogels. Nanotechnology 2010, 21, 115502.

(34) Ganguly, S.; Zhou, C.; Morelli, D.; Sakamoto, J.; Brock, S. L. Synthesis and Characterization of Telluride Aerogels: Effect of Gelation on Thermoelectric Performance of Bi 2Te 3 and Bi 2-XSb XTe 3 Nanostructures. J. Phys. Chem. C 2012, 116, 17431-17439.

(35) Matter, F.; Luna, A. L.; Niederberger, M. From Colloidal Dispersions to Aerogels: How to Master Nanoparticle Gelation. Nano Today 2020, 30, 100827.

(36) Smith, A. M.; Nie, S. Semiconductor Nanocrystals: Structure, Properties, and Band Gap Engineering. Acc. Chem. Res. 2010, 43, 190-200.

(37) Reiss, P.; Protière, M.; Li, L. Core/Shell Semiconductor Nanocrystals. Small 2009, 5, 154-168. 
(38) Carbone, L.; Cozzoli, P. D. Colloidal Heterostructured Nanocrystals: Synthesis and Growth Mechanisms. Nano Today 2010, 5, 449-493.

(39) Yu, H.; Brock, S. L. Effects of Nanoparticle Shape on the Morphology and Properties of Porous CdSe Assemblies (Aerogels). ACS Nano 2008, 2, 1563-1570.

(40) Gao, X.; Esteves, R. J.; Luong, T. T. H.; Jaini, R.; Arachchige, I. U. Oxidation-Induced Self-Assembly of Ag Nanoshells into Transparent and Opaque Ag Hydrogels and Aerogels. J. Am. Chem. Soc. 2014, 136, 7993-8002.

(41) Naskar, S.; Miethe, J. F.; Sanchez-Paradinas, S.; Schmidt, N.; Kanthasamy, K.; Behrens, P.; Pfnür, H.; Bigall, N. C. Photoluminescent Aerogels from Quantum Wells. Chem. Mater. 2016, 28, 2089-2099.

(42) Nasilowski, M.; Mahler, B.; Lhuillier, E.; Ithurria, S.; Dubertret, B. Two-Dimensional Colloidal Nanocrystals. Chem. Rev. 2016, 116, 10934-10982.

(43) Lhuillier, E.; Pedetti, S.; Ithurria, S.; Nadal, B.; Heuclin, H.; Dubertret, B. Two-Dimensional Colloidal Metal Chalcogenides Semiconductors: Synthesis, Spectroscopy, and Applications. Acc. Chem. Res. 2015, 48, 22-30.

(44) Naskar, S.; Freytag, A.; Deutsch, J.; Wendt, N.; Behrens, P.; Köckritz, A.; Bigall, N. C. Porous Aerogels from Shape-Controlled Metal Nanoparticles Directly from Nonpolar Colloidal Solution. Chem. Mater. 2017, 29, 9208-9217.

(45) Gill, S. K.; Hope-Weeks, L. J. Monolithic Aerogels of Silver Modified Cadmium Sulfide Colloids. Chem. Commun. 2009, 0, 4384.

(46) Gill, S. K.; Brown, P.; Hope-Weeks, L. J. Gold Modified Cadmium Sulfide Aerogels. J. Sol-Gel Sci. Technol. 2011, 57, 68-75.

(47) Arachchige, I. U.; Brock, S. L. Highly Luminescent QuantumDot Monoliths. J. Am. Chem. Soc. 2007, 129, 1840-1841.

(48) Sanchez-Paradinas, S.; Dorfs, D.; Friebe, S.; Freytag, A.; Wolf, A.; Bigall, N. C. Aerogels from CdSe/CdS Nanorods with Ultra-Long Exciton Lifetimes and High Fluorescence Quantum Yields. Adv. Mater. 2015, 27, 6152-6156.

(49) Yao, Q.; Arachchige, I. U.; Brock, S. L. Expanding the Repertoire of Chalcogenide Nanocrystal Networks: $\mathrm{Ag}_{2}$ Se Gels and Aerogels by Cation Exchange Reactions. J. Am. Chem. Soc. 2009, 131, 2800-2801

(50) Li, H.; Zanella, M.; Genovese, A.; Povia, M.; Falqui, A.; Giannini, C.; Manna, L. Sequential Cation Exchange in Nanocrystals: Preservation of Crystal Phase and Formation of Metastable Phases. Nano Lett. 2011, 11, 4964-4970.

(51) De Trizio, L.; Manna, L. Forging Colloidal Nanostructures via Cation Exchange Reactions. Chem. Rev. 2016, 116, 10852-10887.

(52) Son, D. H.; Hughes, S. M.; Yin, Y.; Alivisatos, A. P. Cation Exchange Reactions in Ionic Nanocrystals. Science (Washington, DC, U. S.) 2004, 306, 1009-1012.

(53) Lesnyak, V.; Wolf, A.; Dubavik, A.; Borchardt, L.; Voitekhovich, S. V.; Gaponik, N.; Kaskel, S.; Eychmüller, A. 3D Assembly of Semiconductor and Metal Nanocrystals: Hybrid CdTe/Au Structures with Controlled Content. J. Am. Chem. Soc. 2011, 133, 13413-13420.

(54) Nahar, L.; Esteves, R. J. A.; Hafiz, S.; Özgür, Ü.; Arachchige, I. U. Metal-Semiconductor Hybrid Aerogels: Evolution of Optoelectronic Properties in a Low-Dimensional CdSe/Ag Nanoparticle Assembly. ACS Nano 2015, 9, 9810-9821.

(55) Wendt, R.; Märker, B.; Dubavik, A.; Herrmann, A. K.; Wollgarten, M.; Rakovich, Y. P.; Eychmüller, A.; Rademann, K.; Hendel, T. Versatile H2O2-Driven Mixed Aerogel Synthesis from CdTe and Bimetallic Noble Metal Nanoparticles. J. Mater. Chem. C 2017, 5, 10251-10259.

(56) Wolf, A.; Lesnyak, V.; Gaponik, N.; Eychmüller, A. QuantumDot-Based (Aero)Gels: Control of the Optical Properties. J. Phys. Chem. Lett. 2012, 3, 2188-2193.

(57) Kodanek, T.; Freytag, A.; Schlosser, A.; Naskar, S.; Härtling, T.; Dorfs, D.; Bigall, N. C. Macroscopic Aerogels with Retained Nanoscopic Plasmonic Properties. Z. Phys. Chem. 2018, 232, 16751689.
(58) Davis, J. L.; Silva, K. L.; Brock, S. L. Exploiting Kinetics for Assembly of Multicomponent Nanoparticle Networks with Programmable Control of Heterogeneity. Chem. Commun. 2020, 56, 458-461.

(59) Cai, B.; Hübner, R.; Sasaki, K.; Zhang, Y.; Su, D.; Ziegler, C.; Vukmirovic, M. B.; Rellinghaus, B.; Adzic, R. R.; Eychmüller, A. CoreShell Structuring of Pure Metallic Aerogels towards Highly Efficient Platinum Utilization for the Oxygen Reduction Reaction. Angew. Chem., Int. Ed. 2018, 57, 2963-2966.

(60) Rusch, P.; Schremmer, B.; Strelow, C.; Mews, A.; Dorfs, D.; Bigall, N. C. Nanocrystal Aerogels with Coupled or Decoupled Building Blocks. J. Phys. Chem. Lett. 2019, 10, 7804-7810.

(61) Heiligtag, F. J.; Airaghi Leccardi, M. J. I.; Erdem, D.; Süess, M. J.; Niederberger, M. Anisotropically Structured Magnetic Aerogel Monoliths. Nanoscale 2014, 6, 13213-13221.

(62) Leventis, N.; Elder, I. A.; Long, G. J.; Rolison, D. R. Using Nanoscopic Hosts, Magnetic Guests, and Field Alignment to Create Anisotropic Composite Gels and Aerogels. Nano Lett. 2002, 2, 63-67.

(63) Kim, J.; Nakanishi, H.; Pollanen, J.; Smoukov, S.; Halperin, W. P.; Grzybowski, B. A. Nanoparticle-Loaded Aerogels and Layered Aerogels Cast from Sol-Gel Mixtures. Small 2011, 7, 2568-2572.

(64) Korala, L.; Li, L.; Brock, S. L. Transparent Conducting Films of CdSe(ZnS) Core(Shell) Quantum Dot Xerogels. Chem. Commun. 2012, 48, 8523-8525.

(65) Korala, L.; Wang, Z.; Liu, Y.; Maldonado, S.; Brock, S. L. Uniform Thin Films of CdSe and CdSe(ZnS) Core(Shell) Quantum Dots by Sol-Gel Assembly: Enabling Photoelectrochemical Characterization and Electronic Applications. ACS Nano 2013, 7, 1215-1223.

(66) Miethe, J. F.; Luebkemann, F.; Schlosser, A.; Dorfs, D.; Bigall, N. C. Revealing the Correlation of the Electrochemical Properties and the Hydration of Inkjet Printed CdSe/CdS Semiconductor Gels. Langmuir 2020, 36, 4757.

(67) Lübkemann, F.; Anselmann, R.; Kodanek, T.; Bigall, N. C. Inkjet Printing of Aqueous Photoluminescent CdSe/CdS Nanorods on Solid Substrates. Chem. Ing. Tech. 2017, 89, 807-813.

(68) Lübkemann, F.; Miethe, J. F.; Steinbach, F.; Rusch, P.; Schlosser, A.; Zámbó, D.; Heinemeyer, T.; Natke, D.; Zok, D.; Dorfs, D.; Bigall, N. C. Patterning of Nanoparticle-Based Aerogels and Xerogels by Inkjet Printing. Small 2019, 15, 1902186. 